\title{
Factors driving mortality and growth at treeline: a 30-year experiment of 92000 conifers
}

\author{
Ignacio Barbeito, ${ }^{1,3}$ Melissa A. Dawes, ${ }^{1}$ Christian Rixen, ${ }^{1}$ Josef Senn, ${ }^{2}$ and Peter Bebi ${ }^{1}$ \\ ${ }^{1}$ WSL Institute for Snow and Avalanche Research (SLF), Flüelastrasse 11, CH-7260 Davos, Switzerland \\ ${ }^{2}$ Swiss Federal Institute for Forest, Snow and Landscape Research (WSL), CH-8093 Birmensdorf, Switzerland
}

\begin{abstract}
Understanding the interplay between environmental factors contributing to treeline formation and how these factors influence different life stages remains a major research challenge. We used an afforestation experiment including 92000 trees to investigate the spatial and temporal dynamics of tree mortality and growth at treeline in the Swiss Alps. Seedlings of three high-elevation conifer species (Larix decidua, Pinus mugo ssp. uncinata, and Pinus cembra) were systematically planted along an altitudinal gradient at and above the current treeline (2075 to $2230 \mathrm{~m}$ above sea level [a.s.l.]) in 1975 and closely monitored during the following 30 years. We used decision-tree models and generalized additive models to identify patterns in mortality and growth along gradients in elevation, snow duration, wind speed, and solar radiation, and to quantify interactions between the different variables. For all three species, snowmelt date was always the most important environmental factor influencing mortality, and elevation was always the most important factor for growth over the entire period studied. Individuals of all species survived at the highest point of the afforestation for more than 30 years, although mortality was greater above $2160 \mathrm{~m}$ a.s.1., $50-100 \mathrm{~m}$ above the current treeline. Optimal conditions for height growth differed from those for survival in all three species: early snowmelt (ca. day of year 125-140 [where day 1 is 1 January]) yielded lowest mortality rates, but relatively later snowmelt (ca. day 145-150) yielded highest growth rates. Although snowmelt and elevation were important throughout all life stages of the trees, the importance of radiation decreased over time and that of wind speed increased. Our findings provide experimental evidence that tree survival and height growth require different environmental conditions and that even small changes in the duration of snow cover, in addition to changes in temperature, can strongly impact tree survival and growth patterns at treeline. Further, our results show that the relative importance of different environmental variables for tree seedlings changes during the juvenile phase as they grow taller.
\end{abstract}

Key words: afforestation; elevation gradient; height growth; Larix decidua; mortality; Pinus cembra; Pinus mugo ssp. uncinata; physiological threshold; snowmelt date; Swiss Alps; treeline.

\section{INTRODUCTION}

The high-elevation limit of alpine forests is one of the most conspicuous transitions between vegetation types in mountain regions worldwide. In the present study, we refer to "treeline" as the line connecting the highest patches of forest within a given slope (sensu Körner 1998). Interest in treelines is currently increasing, as trees are occurring at higher elevations than in the past in many areas (Kullman 2007, Vittoz et al. 2008, Harsch et al. 2009) and existing treeline trees have exhibited increased growth rates (Rolland et al. 1998, Motta and Nola 2001). As changes in the treeline position will have important implications for the services and functions provided by mountain ecosystems (Grace et al. 2002), it is particularly important to understand the factors that influence mortality and growth of trees at their upper

Manuscript received 28 February 2011; revised 4 August 2011; accepted 12 August 2011. Corresponding Editor: M. C. Wimberly.

${ }^{3}$ E-mail: barbeito@slf.ch elevation limit. However, despite extensive research, many uncertainties remain regarding the reasons for the formation of this ecological boundary (Wardle 1981, Körner 1998, Grace et al. 2002). In particular, the confounding effects of temperature, snow cover duration, and growing-season length on seedling survival and establishment and on the growth of young trees make it difficult to pinpoint precise causes for treeline formation.

In the absence of anthropogenic influence or largescale disturbances such as insect outbreaks, avalanches, or fire, the location of the alpine treeline is generally considered to be primarily driven by growing-season temperatures (Körner 2003, Körner and Paulsen 2004). However, at a more localized scale, treeline patterns are more complex (Holtmeier and Broll 2005), and the exact treeline position can be influenced by microclimatic conditions such as aspect, wind velocity, solar radiation, or the duration of snow cover (Häsler et al. 1999, Körner and Paulsen 2004, Wieser and Tausz 2007). Other factors that might contribute to treeline formation 
include winter desiccation (i.e., damage to needles and branches caused by late winter water losses not being replaced because of frozen soil or stem bases; Tranquillini 1979), or non-climatic factors, such as fungal diseases associated with snowpack (Senn 1999, Körner 2003). Understanding the interplay between factors influencing treeline formation remains a major research challenge.

Another obstacle in understanding treeline dynamics is that different life stages of trees may be susceptible to different environmental factors. Most trees at the treeline die at younger ages than in the adjacent closed forests (e.g., Hättenschwiler and Smith 1999), except in the case of large-scale disturbances (Kullman 1997). Single freezing events during the growing season commonly kill seedlings and small trees, and such episodes occur more frequently than those that kill mature trees (Kullman 1986, Smith et al. 2003). Therefore, the first years of growth constitute a bottleneck in the recruitment process and can be critical for determining treeline position (Germino et al. 2002, Wieser and Tausz 2007). Whereas physical conditions close to the ground surface often influence tree growth and mortality in early years of growth (Weisberg and Baker 1995, Smith et al. 2003, Daniels and Veblen 2004, Munier et al. 2010), needles and shoots may become less coupled to the ground-level environment when trees become taller (Wardle 1981, Grace et al. 2002, Li and Yang 2004, Wieser and Tausz 2007). Although a great deal of knowledge has been accumulated on limiting factors near treeline (Tranquillini 1979, Körner 2003, Sveinbjörnsson 2000 [representing a carbon balance perspective], Smith et al. 2003 [representing the seedling perspective]), to date there have been only a few studies of how these factors change over time during the juvenile phase of trees (Weisberg and Baker 1995, Li and Yang 2004). Furthermore, to the best of our knowledge, no study has investigated if the same environmental factors at treeline drive both survival and height growth.

Although the European Alps are certainly the most intensively studied of all the high mountain ranges in the world, long-term observations of treeline distributions are rare (Gehrig-Fasel et al. 2007). Intensive land-use further complicates treeline studies in many European mountain ranges, where the centuries-long history of seasonal livestock grazing of alpine pastures has significantly depressed the treeline in many places (in the Alps, Ellenberg 1988, Körner 1998, Wallentin et al. 2008; in the Pyrenees, Camarero et al. 2006; and in the Scandes Mountains, Speed et al. 2010). Therefore, observational studies of current treelines in these regions might not provide relevant information about environmental factors that influence mortality and growth patterns at the natural high-elevation limit of tree existence.

To overcome these obstacles and to help understand the spatial and temporal dynamics of tree mortality and growth during the juvenile phase, we used a large afforestation experiment located at the treeline in the Swiss Alps. Three of the most widespread tree species in the treeline ecotones of the European Alps, Cembran pine (Pinus cembra L.), mountain pine (Pinus mugo ssp. uncinata Ramond), and European larch (Larix decidua L.), were systematically planted and closely monitored during the following 30 years. The afforestation covers an altitudinal gradient that extends to $2230 \mathrm{~m}$ above sea level (a.s.l.), which provided the unique opportunity to study how trees perform $>100 \mathrm{~m}$ above the existing treeline. Investigating planted trees enabled us to study the effects of environmental factors on tree mortality and growth alone, excluding the environmental filters of seed production and initial seedling establishment after germination. We addressed the following questions: (1) Can trees survive above the current treeline in the European Alps? (2) Are environmental factors that influence spatial patterns of mortality the same that influence height growth? (3) Does the relative importance of environmental variables influencing spatial patterns of mortality and height growth change over the first 30 years after planting?

\section{Material and Methods}

\section{Study area}

The study was conducted at the 5-ha Stillberg longterm afforestation research area near Davos in the Central Alps (eastern Switzerland; $47^{\circ} 28^{\prime}$ N, $7^{\circ} 30^{\prime}$ E). In 1975, 92 000 seedlings of three treeline species of highelevation provenances, one-year old $L$. decidua, threeyear old $P$. mugo, and five-year old $P$. cembra, were systematically planted in 4052 square plots $(\sim 1350$ plots for each species) of $3.5 \times 3.5 \mathrm{~m}$ arranged in a quadratic grid, with 25 trees in each plot planted into the original dwarf shrub community at $70-\mathrm{cm}$ intervals. Before analyzing the 30-year data, we determined the position of the treeline through a GIS analysis of the highest forest patches (minimum size of $500 \mathrm{~m}^{2}$ ) in the valleys around the study area. A $2 \times 2 \mathrm{~km}$ moving window algorithm yielded a treeline elevation of $2100 \mathrm{~m}$ a.s.l., irrespective of exposure, which corresponds to the findings for the Swiss Alps by Paulsen and Körner (2001). Therefore, the afforestation starts approximately at the treeline as defined in the Introduction and covers an altitudinal gradient of more than $150 \mathrm{~m}$ (2075-2230 $\mathrm{m}$ a.s.l.). It is located on a northeast-facing slope featuring steep, topographically highly structured terrain (Fig. 1). The soil (classified as Ranker/Lithic Haplumbrept) typically consists of a $10 \mathrm{~cm}$ deep organic top layer on siliceous (Paragneis) bedrock (Schönenberger and Frey 1988). At a meteorological station located near the bottom of the Stillberg afforestation (2090 $\mathrm{m}$ a.s.1.), mean annual precipitation averaged 1150 $\mathrm{mm}$ and air temperature averaged $2.0^{\circ} \mathrm{C}$ over the year (1975-2005 mean). Snow can fall at any time of the year, but continuous winter snow cover generally lasts from mid-October to the end of May, with an annual 

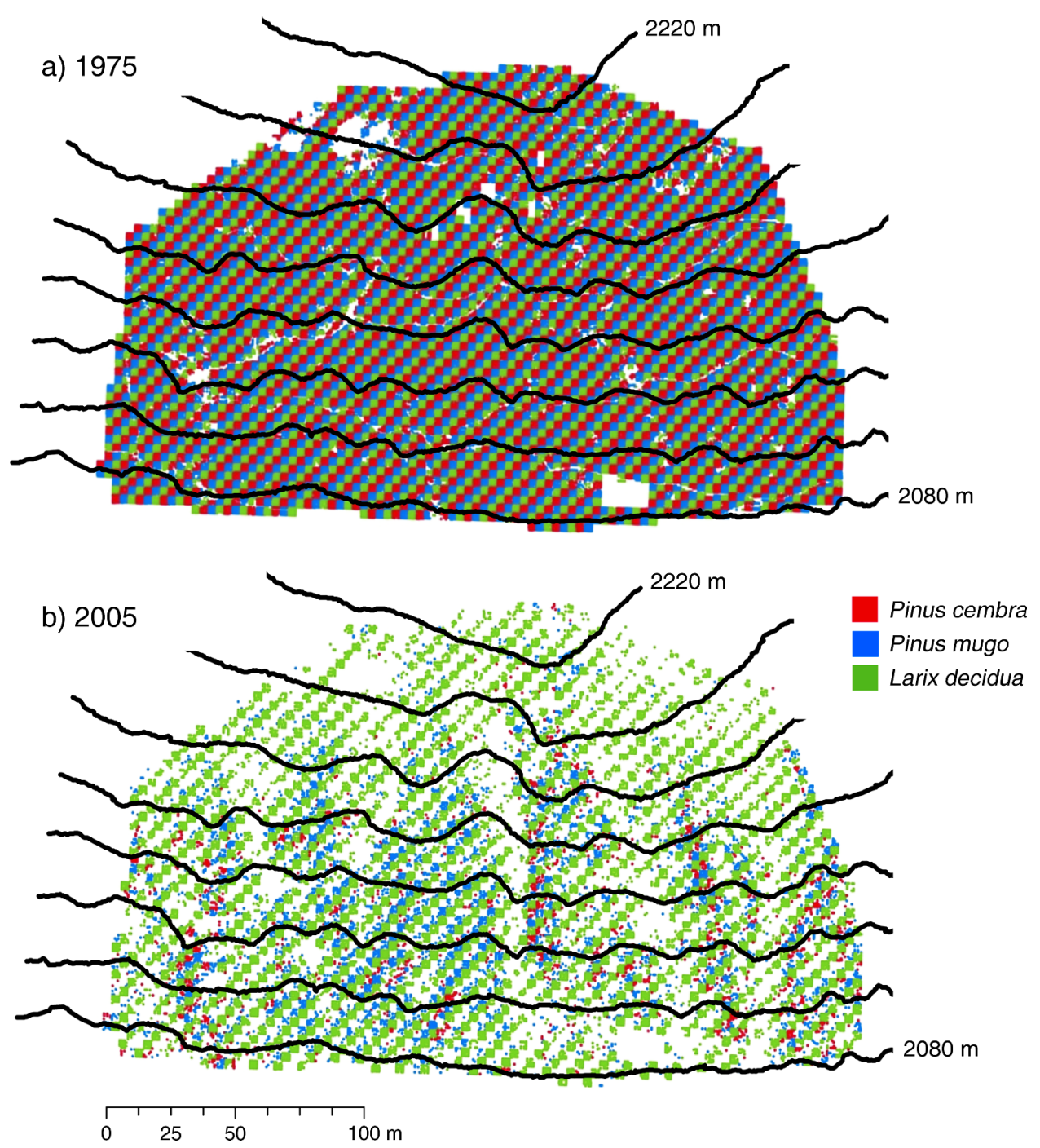

FIG. 1. Tree species distribution map of Stillberg, Central Alps, Switzerland, in: (a) 1975 and (b) 2005.

maximum snow depth of $1.46 \mathrm{~m}$ (1975-2005 mean). Mean daily air temperature ( $2 \mathrm{~m}$ height) averaged over the growing season ranged from $7.0^{\circ}$ to $10.6^{\circ} \mathrm{C}$, during the 30-year period from 1975-2005, with a significant increase in air temperature in this period $(P<0.01$; Appendix A). For these averages, we defined the growing season as the first date when mean daily temperature rose above $3.2^{\circ} \mathrm{C}$ in spring and fell below $3.2^{\circ} \mathrm{C}$ for more than two contiguous days in autumn (Körner and Paulsen 2004).

\section{Data}

All individuals of the three tree species were visited annually from 1975 to 1995 to assess mortality, and a final visit was made in 2005. Height of the surviving trees was recorded every 10 years (1985, 1995, and 2005). Height was significantly correlated with total biomass for all three species in a sample of trees harvested from the afforestation in 1998 (Bernouilli 1998). This parameter was, therefore, representative of overall tree growth, as well as being possible to measure repeatedly on almost 100000 trees. In addition to observations of trees, various micro-site features were recorded at the time of tree establishment for each square plot of 25 trees (Schönenberger and Frey 1988), including elevation (m a.s.l.), slope (\%), solar radiation during the growing season $\left(\mathrm{W} / \mathrm{m}^{2}\right.$, mean value of three years 1980 1982), wind velocity (m/s, measured in 1971 , four years before planting), initial snowmelt date in spring (averaged between 1975 and 1982), avalanche frequency, soil type, humus form, and vegetation type (mainly dwarf shrub communities). Trees were not tall enough to influence radiation when it was measured, and therefore this parameter represents microtopographic differences throughout the afforestation rather than shading from tree canopies. Radiation was measured with a star- 
pyranometer in 2745 points distributed in a $5 \times 5 \mathrm{~m}$ grid covering the whole afforestation. Radiation was strongly influenced by slope and aspect and therefore was highly correlated with both variables. Wind speed was measured at $1 \mathrm{~m}$ height with 60 anemometers distributed in a $20 \times 20 \mathrm{~m}$ grid covering the whole afforestation. Similar to radiation, snowmelt date was only recorded at the time of tree establishment and is more influenced by topography than by precipitation and temperature (Appendices A and B). There was no significant change in snowmelt date over the 30 -year study period $(P=$ 0.08; Appendix A). Further, annual snow height measurements from 18 positions throughout Stillberg show no change in the snow distribution pattern across the afforestation over the entire study period (P. Bebi, unpublished data). This information supports the assumption that the snowmelt date recorded at the beginning of the study was relevant for the entire study period. $P$. mugo trees were typically covered by snow until a few weeks before the indicated snowmelt dates for the whole 30 -year period. Some $L$. decidua trees in the lower part of the afforestation (i.e., below $2100 \mathrm{~m}$ ) were partially exposed above the snow cover after approximately 1995 .

We selected four environmental predictors for explaining mortality and growth: elevation (2075-2230 m a.s.1.), solar radiation $\left(60-205 \mathrm{~W} / \mathrm{m}^{2}\right)$, date of disappearance of snow cover in spring (snowmelt date; day 123 [3 May] to day 170 [19 June]), and wind velocity $(0.95-3.42 \mathrm{~m} / \mathrm{s})$. Our choice was based on preliminary analysis that showed that these variables were the most relevant and that they were not highly correlated $\left(r^{2}<\right.$ 0.3 ). Neighbor interactions might be important in a natural treeline environment with a diverse age structure where small seedlings are facilitated by larger existing trees (e.g., Maher and Germino 2006). In the context of this afforestation, however, neighbor interactions were confounded with micro-site effects (i.e., more neighbors in micro-sites most favorable for survival) and were therefore considered, but not included, in the final analysis.

\section{Statistical analysis}

We tested for differences in species mortality and height growth using two conceptually different nonparametric regression approaches: decision-tree based analysis (DT; Breiman et al. 1984) and generalized additive models (GAMs; Hastie and Tibshirani 1990). These statistical techniques are appropriate for highly nonlinear relationships between the response variable and the set of explanatory variables and can account for interactions among variables. GAMs are a useful exploratory tool for describing single variable trends and statistically detecting thresholds, while the topology and hierarchical structure of DT analysis are better suited for identifying complex relationships among the predictor variables and their relative importance.
DTs are models in which the response variable is split into increasingly homogeneous subsets by recursive partitioning on a set of categorical or numerical predictor variables, with results displayed on a dendrogram (Déath and Fabricius 2000). DTs offer the additional advantage of automatically identifying interactions among variables. We performed conditional inference DTs on mortality in the overlapping periods 1975-1985, 1975-1995, and 1975-2005. We chose to study mortality in cumulative periods to avoid bias in the sample data (i.e., trees would have disappeared from certain micro-sites in later periods). DTs on tree height growth were performed for the three species studied in three 10-year periods, 1975-1985, 1985-1995, and 19952005. For this analysis we used only the trees that were alive in 2005 to maintain the same sample size and make comparisons between the three periods more meaningful. We used an unbiased classification tree algorithm that employs $P$ values for variable selection and as a stopping criterion (Hothorn et al. 2006). We chose a conservative value of $P<0.001$ for our study because of the large sample size.

Simple DT models can be unstable when small changes are made in the learning data (i.e., the portion of the data used to grow the tree; Strobl et al. 2009). Therefore, we additionally used random forests, a technique that combines the prediction of many independent regression tree models into a robust composite model (Cutler et al. 2007). Another advantage of random forests is that, by permutation of independent variables, they provide measures of variable importance. A random forest of 100 bootstrap samples with unbiased variable selection (to avoid a preference for certain variables due to their scale of measurement or number of categories) was used to estimate the relative importance of the predictor variables. The variable importance measure is calculated as follows (Breiman 2001): By randomly permuting the predictor variable, its original association with the response is broken. When the permuted predictor variable, together with the remaining non-permuted predictor variables, are used to predict the response for the out-of-bag observations (i.e., portion of the data not used to grow the tree), the prediction accuracy (i.e., the number of observations classified correctly) decreases substantially if the original variable was associated with the response. Thus, the variable importance is the difference in prediction accuracy before and after permuting the variable, averaged over all decision trees (Breiman 2001). To account for the correlation between the predictor variables, we used a conditional permutation scheme for the computation of the variable importance measure (Strobl et al. 2008). We compared the ranking of the predictor variables instead of the absolute values of variable importance measures, as suggested by Strobl et al. (2009).

GAMs are a nonparametric extension of multiple linear regression in which a link function is related to the 
predictor variables by a number of smoothing functions rather than by a coefficient, typically resulting in nonlinear shapes that are more representative of the data (Hastie and Tibshirani 1990). For each tree species, we developed GAMs with mortality and height growth as the response variables and the two most important variables as determined from the DTs (elevation and snowmelt date) as the predictor variables.

We used the "party" package (Hothorn et al. 2006) in R (R Development Core Team 2009) to estimate the decision trees, the random forests, and the variable importance for each of the random forests. GAMs were conducted in R with the "mgcv" package (Wood 2006). The spatial autocorrelation of the GAM models was tested using Moran's $I$ analysis of the model residuals (Fortin and Dale 2005).

\section{RESUlts}

\section{Mortality}

Thirty years after planting, trees of each species survived at the highest elevation of the afforestation, which was $>100 \mathrm{~m}$ higher than the defined treeline position of $2100 \mathrm{~m}$ (Fig. 1). The dominant survivor was L. decidua ( $31 \%$ mortality), followed by P. mugo ( $82 \%$ mortality), and relatively few $P$. cembra remained alive (95\% mortality) (Fig. 2). For all three species, mortality rates were highest during the first 15 years of the study period (Fig. 2). Spatial patterns of mortality of all three species over the entire 30-year period were highly correlated with the date of snow disappearance in spring and with elevation, as identified by the conditional inference DTs, where these two variables generally represented the first two splits after species (Fig. 3; Appendix C). Mortality of both pine species was $>90 \%$ in areas where snowmelt date was later than day 147 (27 May), with the highest mortality rate for $P$. cembra above $2157 \mathrm{~m}$ ( $>99 \%$ mortality). The same snowmelt date was critical for L. decidua ( $>30 \%$ mortality), although the mortality rate was further increased to $>50 \%$ at locations where the snowmelt date was later than day 152 (2 June). Similarly, GAMs revealed a sharp increase in mortality above critical thresholds of elevation and snowmelt date (Figs. 3 and 4a, b). The three tree species showed a sharp increase in mortality at elevations above ca. $2160 \mathrm{~m}$ a.s.l. (Fig. 4a) and a general pattern of lower mortality at locations with an earlier snowmelt date in the spring (highest survival before day 140 , where day 1 is 1 January [20 May]). However, $P$. cembra showed a trend of higher mortality at locations with a later snowmelt date, while in both $P$. mugo and $L$. decidua, there was a threshold around day 145 (25 May), after which mortality increased sharply (Fig. 4b). In $L$. decidua only, the mortality rate was also higher at locations with very early snowmelt dates (day 125-130 [5-10 May]). The absence of spatial autocorrelation in the residuals of the GAMs confirmed that in our study there was no need to consider neighbor spatial interactions.

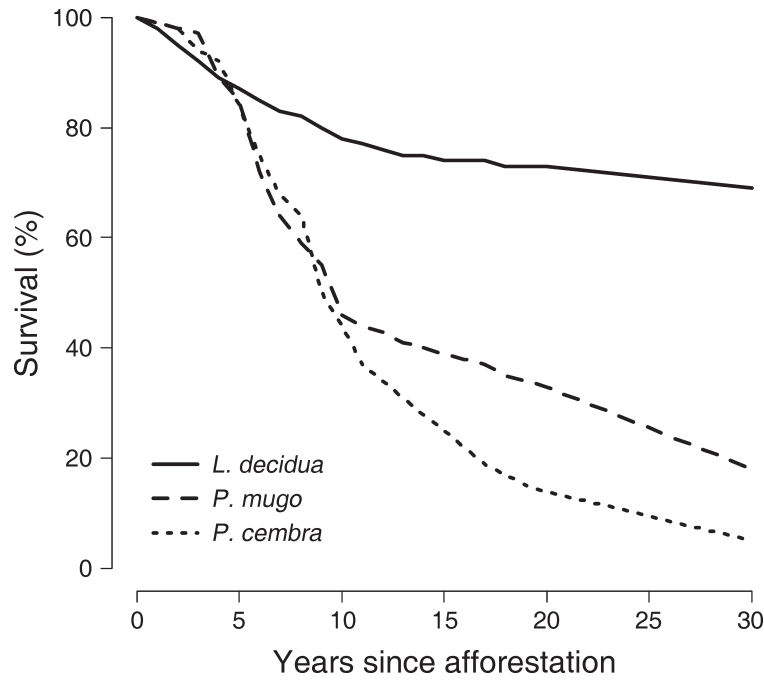

FIG. 2. Survival curves for three high-elevation conifers (Larix decidua, Pinus mugo ssp. uncinata, and Pinus cembra) for the period 1975-2005. For each species, survival is expressed as a percentage of the $\sim 30000$ trees per species planted as seedlings.

The permutation variable importance graphs for the three periods analyzed similarly indicated that snowmelt date and elevation were consistently the most important environmental variables affecting mortality (Fig. 5). Additionally, as trees grew taller in the last 10-year period analyzed, wind velocity had a larger influence on tree mortality (Fig. 5).

\section{Height growth}

During each of the three growth periods, height growth of all three species gradually decreased as elevation increased (Fig. 6a; Appendix D). This decrease was exponential in $L$. decidua and almost linear in the pine species. All three species showed a height growth optimum on a later snowmelt date than mortality (ca. day 140-150 [20-30 May]; Fig. 6b; Appendix D). This optimum shifted to a later date over time for the three species. This shift was especially noticeable in P. mugo, which showed an overall trend of more growth at locations with a later snowmelt date in the last 10-year period (maximum at day 155). However, this result could be at least partially an artifact of the (not significant) trend of slightly earlier snowmelt date at the end of the 30-year period compared to when snowmelt measurements were conducted (Appendix A) Species differences in height growth became larger over time (Fig. 7). In the period 1975-1985, trees growing below $2100 \mathrm{~m}$ had the highest growth rates, irrespective of species. In the two following 10-year periods (19851995 and 1995-2005), L. decidua growing below $2100 \mathrm{~m}$ had the highest growth rates, while $P$. cembra and $P$. mugo growing above $2160 \mathrm{~m}$ or with a snowmelt date earlier than day 143 [23 May] showed the lowest growth rates (decision trees for height growth; Appendix B). 


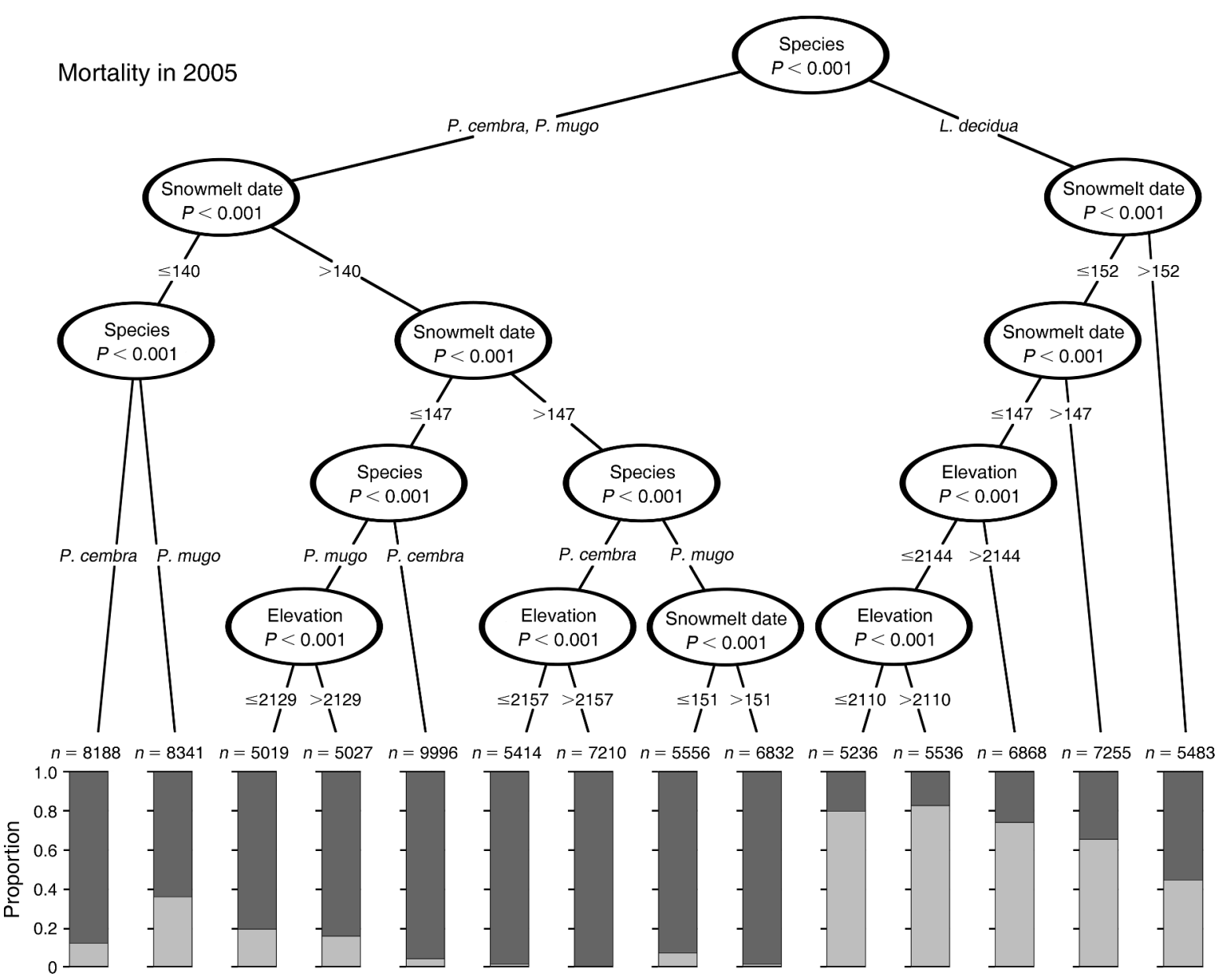

FIG. 3. Decision tree for mortality of all trees in the period 1975-2005. The relative frequencies of both response classes are shown in the inner nodes of the classification tree (the proportion of dead trees is shown in dark gray, and the proportion alive is shown in light gray).

Variable importance graphs indicated that elevation was the most important predictor across the three 10year periods studied (Fig. 7). Radiation became less important over time (second in importance in 1975-1985 and fifth in importance in 1995-2005; Fig. 7), while wind velocity became a slightly more important variable in the two last 10 -year periods (more important than radiation; Fig. 7).

\section{DisCusSION}

\section{Physiological limit of established trees}

Trees of all three species survived $>30$ years after the afforestation at elevations above the current treeline, with significantly higher mortality occurring $>50 \mathrm{~m}$ above the treeline. This result represents novel experimental evidence that these tree species can survive above the current treeline when planted as seedlings. Our finding that mortality rates differed strongly between species suggests that predictions for tree survival cannot be generalized over different tree species. However, for this large-scale and long-term study, it was not possible to include detailed micro-site measurements that could have provided a more mechanistic understanding of survival and growth patterns at treeline.

The elevation threshold observed in our study represents the physiological upper limit of tree survival and growth in the climate of the past 30 years. This threshold is different from the existing treeline in the European Alps, which may be lower due to restrictions on germination and seedling establishment and to historical intensive land use, as centuries of grazing have led to depressed treeline positions (e.g., GehrigFasel et al. 2007). Dense cover of alpine vegetation, mainly dwarf shrub communities in the Alps, can strongly inhibit trees' earliest life stages (e.g., Anthelme et al. 2003) and could be even more important for treeline dynamics than temperature (e.g., Dullinger et al. 2004). Land use has certainly been an important factor in the valleys around Stillberg, where grazing at treeline has been documented (Senn 1952). Planting for the purpose of determining the physiological limit of the established trees was especially important in the Alps, 

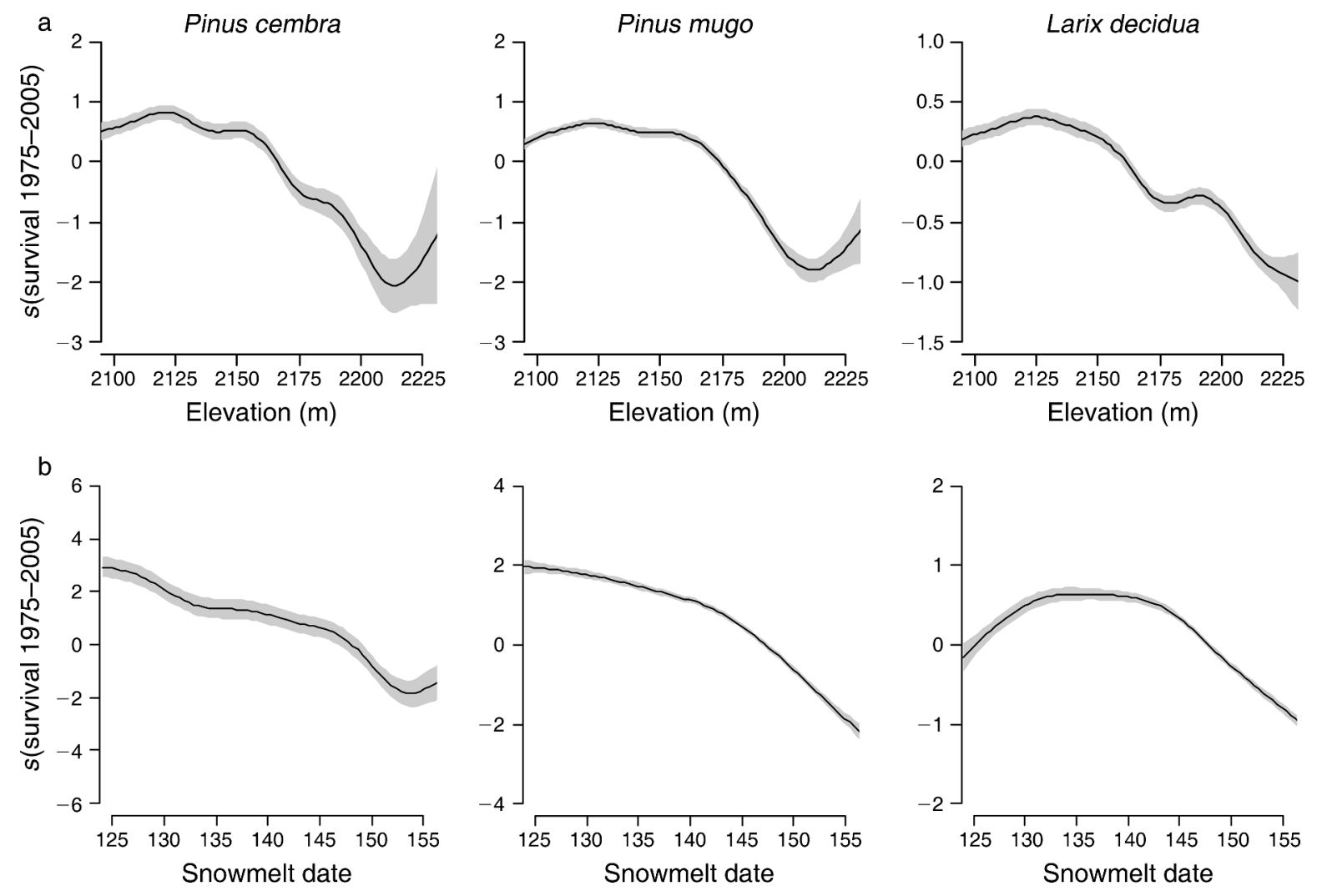

FIG. 4. Estimated generalized additive models (GAM) functions for significant predictors of mortality for the three species during three overlapping periods: (a) elevation and (b) snowmelt date (day of year, where day 1 is 1 January). Each plot shows the relationship of the fitted function with the response, scaled to zero. Values on the $y$-axes are residuals, the smooth-term coefficients (s) fitted from a generalized additive model. The plots include approximate $95 \%$ pointwise CI bands (in light gray).

where observations of treeline patterns are more likely to be obscured by historical land use than in regions with less human influence, such as the Rocky Mountains (Butler et al. 1994), the Polar Urals (Devi et al. 2008), or northern Patagonia (Daniels and Veblen 2004).
Elevation and snow duration influence the treeline position

The sharp increase in tree mortality above $\sim 2160 \mathrm{~m}$ a.s.l. is probably primarily due to a direct lowtemperature limitation (Körner 1998, 2003) combined with indirect effects of temperature stress such as frost
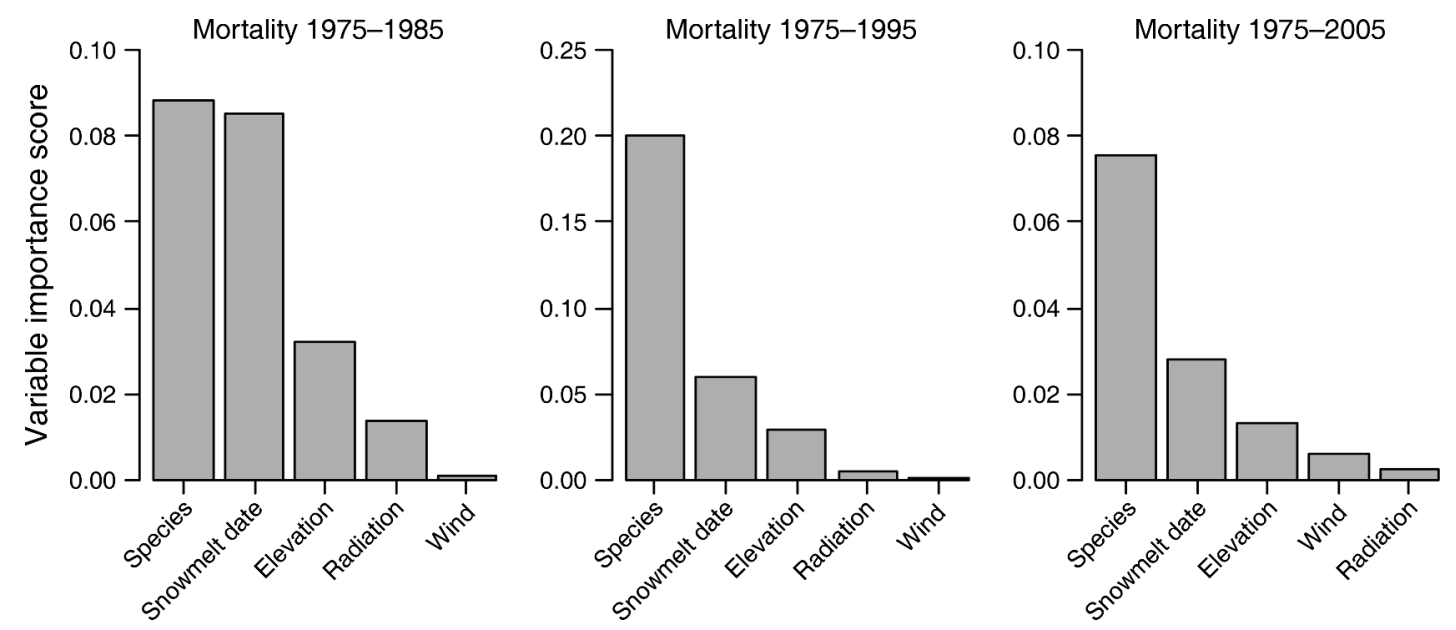

FIG. 5. Permutation variable importance, in rank order, of environmental predictors of mortality, where importance was measured by the drop in classification accuracy after predictor removal in a random forest of 100 decision trees. 

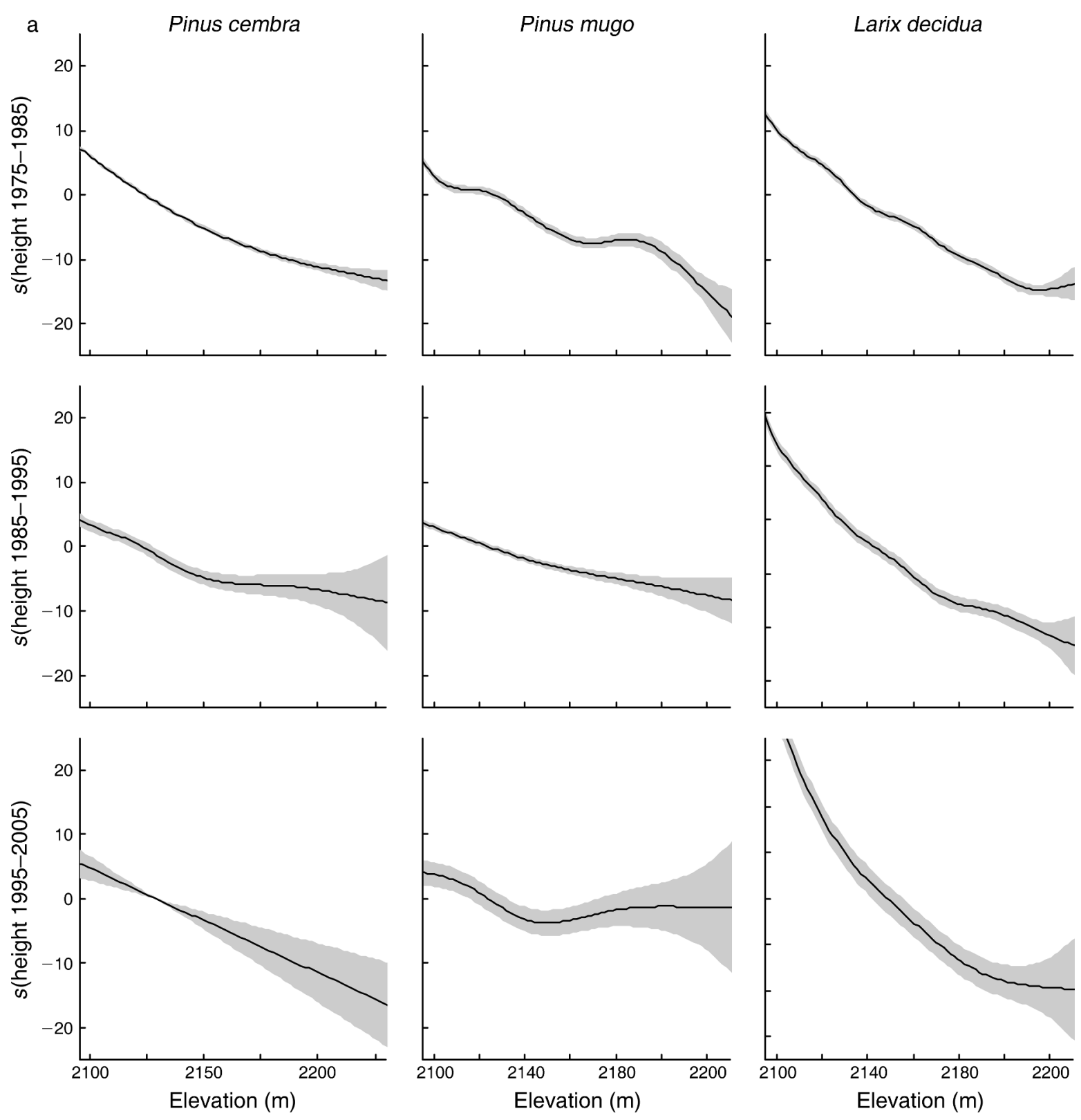

FIG. 6. Estimated GAM functions for significant predictors of height growth during three 10-year periods: (a) elevation and (b) snowmelt date (day of year, where day 1 is 1 January). Each plot shows the relationship of the fitted function with the response, scaled to zero. Values on the $y$-axes are residuals, the smooth-term coefficients $(s)$ fitted from a generalized additive model. The plots include approximate $95 \%$ pointwise CI bands (in light gray).

damage, winter desiccation, or low-temperature photoinhibition (e.g., Germino and Smith 2000, Germino et al. 2002). Previous studies of P. cembra and L. decidua within the treeline ecotone at 2050-2200 $\mathrm{m}$ have shown that growth was positively correlated with summer temperatures (e.g., Carrer and Urbinati 2004, Oberhuber 2004). Further, low temperature during the growing season has been found to restrict tissue formation (e.g., Rossi et al. 2007), and is thus widely considered the primary constraint for tree growth at the treeline. The air temperature records from the meteorological station located near the bottom of the Stillberg afforestation are slightly above the minimum temperature required for tissue formation in woody plants $\left(\sim 5^{\circ} \mathrm{C}\right.$; Körner 1998 , Körner and Paulsen 2004). Increased frequency of frost damage with increasing elevation was observed for $L$. decidua and $P$. cembra at the treeline in Switzerland (Upper Engadine; Müterthies 2002), and a strong positive correlation between elevation and winter desiccation was found in the Rocky Mountains (Glacier National Park; Cairns 2001). 

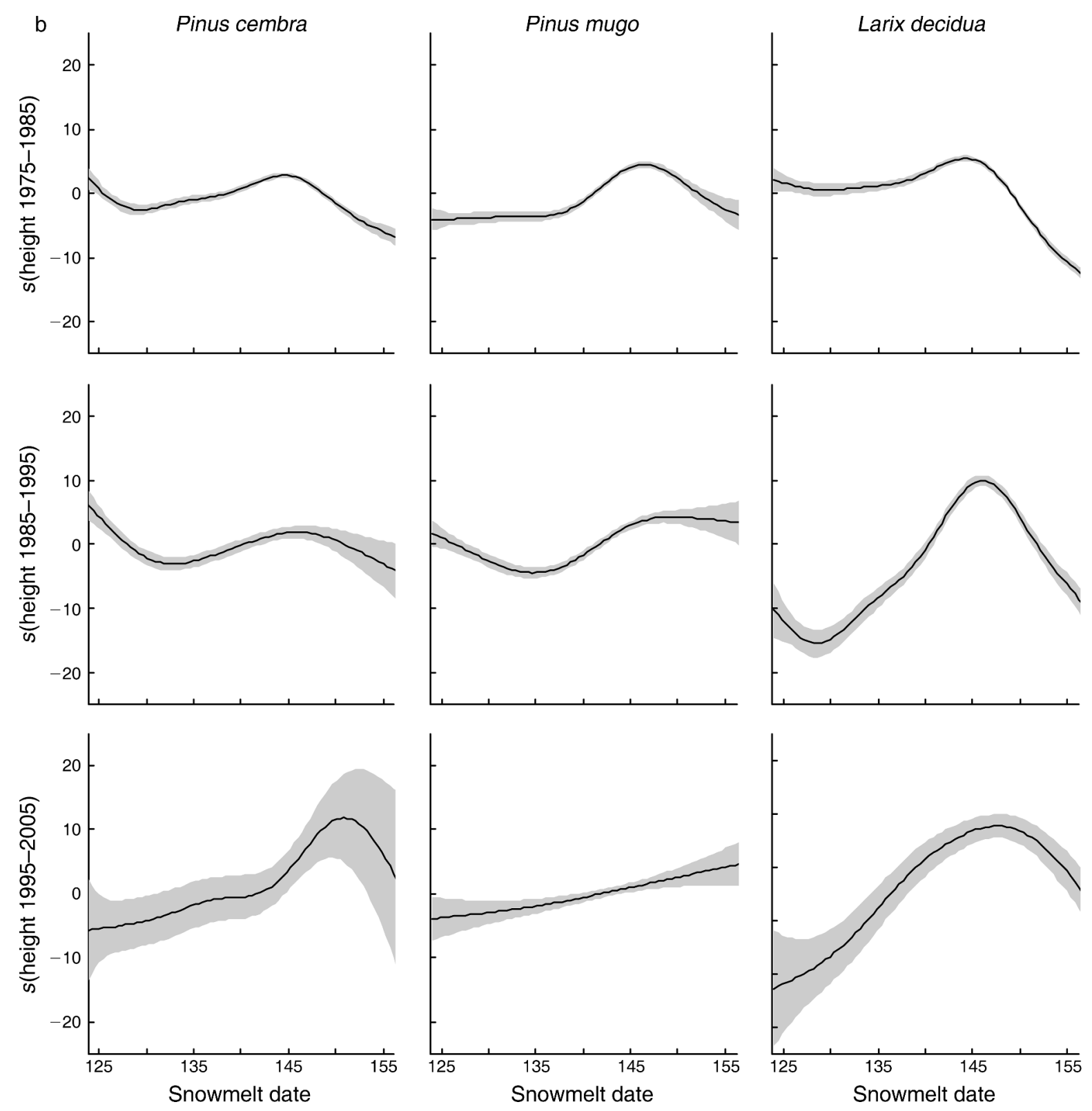

FIG. 6. Continued.

It was also apparent that the spatial pattern of snow duration strongly modified mortality of the three species within a given elevation. In natural treelines, snow cover also plays an important role in tree species distribution. For example, it is well established that $P$. cembra mainly grows in exposed habitats with early snowmelt (Ellenberg 1988). At Stillberg, high mortality of pine species with late snowmelt was primarily related to pathogenic snow fungi (Senn 1999). Although snow fungi are not a well-documented phenomenon, they were identified as a secondary factor causing mortality of Pinus sylvestris growing at treeline in the Swedish Scandes (Kullman 2007) and were responsible for high mortality of Picea mariana at the Arctic treeline of eastern Canada (Auger and Payette 2010). Consequently, our study provides evidence that snow distribution and snow fungi may be a major modifying factor that determines the position of treelines in regions where the negative impacts of snow outweigh the protective role of snow cover (against wind or photoinhibition; e.g., Cairns 2001, Germino et al. 2002). We also found higher mortality in L. decidua at very early snowmelt dates that was not observed in the pine species (Fig. 3b). A possible explanation for this result is that freezing events occur more frequently during the early growing season and frozen soils could have severely limited water uptake (Havranek and 

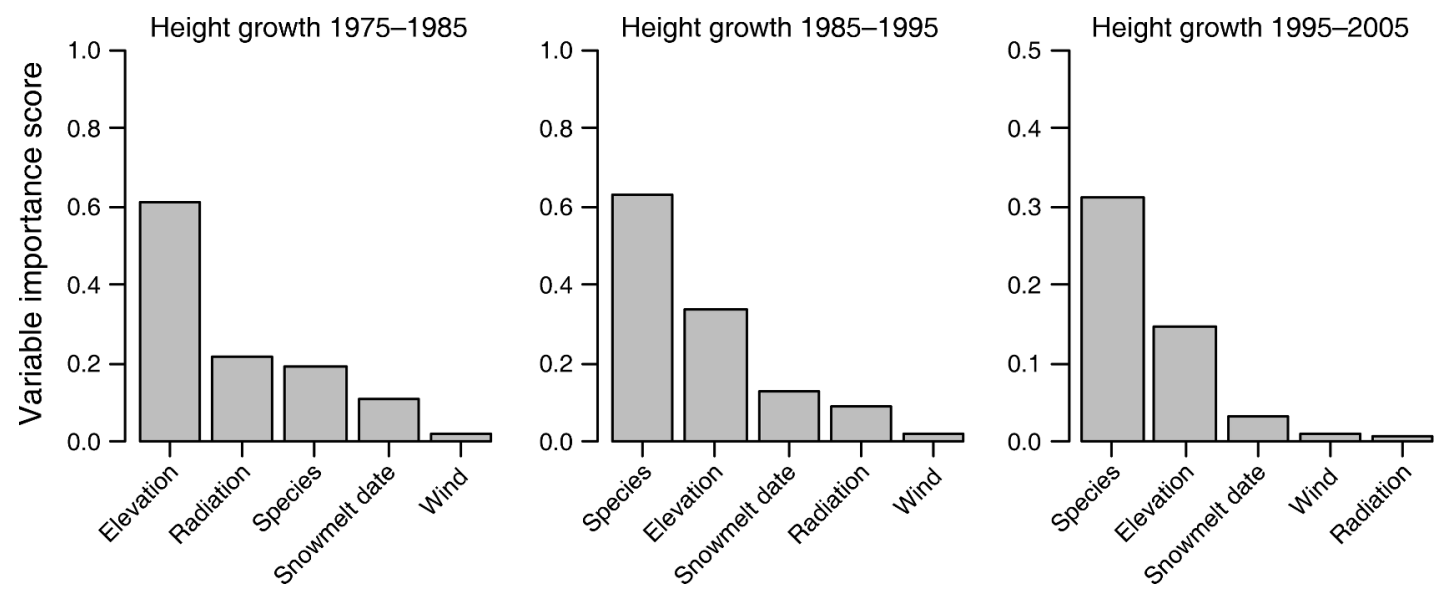

FIG. 7. Permutation variable importance, in rank order, of environmental predictors of height growth, where importance was measured by the drop in classification accuracy after predictor removal in a random forest of 100 decision trees.

Tranquillini 1995). Further, freezing might have directly damaged tissue and hampered survival at sites where the deciduous $L$. decidua trees started to grow at a relatively early date in spring (Martin et al. 2010). In a snow removal experiment at Stillberg, Frey (1983) found that $L$. decidua suffered from severe winter desiccation damage after freezing events, while no damage occurred in $P$. cembra or $P$. mugo individuals. Therefore, $L$. decidua may be more sensitive to freezing events during late winter/the early growing season than the evergreen pines.

\section{Factors driving mortality vs. height growth and their changing importance over time}

Our results indicate that the height growth optimum was at a later snowmelt date than the survival optimum. Despite its influence on mortality, infection by snow fungi did not greatly affect height growth at Stillberg (R. Brücker, unpublished data). Therefore, the factors related to snow cover affecting increased survival did not translate to increased growth. Beneficial effects of delayed snowmelt for growth could be higher water availability during summer (Hättenschwiler and Smith 1999) or protection of aboveground tissues from springtime freezing events (Wipf et al. 2009). Alternatively, longer snow duration provides insulation of the ground from colder air temperatures, which can increase soil temperatures, promote microbial life under the snow, and together with increased water availability, result in an increased nutrient supply for trees at the beginning of the growth period (e.g., Mack et al. 2004).

The 30-year period analyzed showed rather high mortality in both pine species and interesting interspecific differences. These results demonstrate that, although initial establishment after germination is considered a critical bottleneck for survival (Germino et al. 2002, 2006, Wieser and Tausz 2007), the life stages investigated here can also strongly influence mortality patterns. The mortality rates for the three species were highest between 5 and 15 years. During the first years after planting, the highest mortality rates were observed in $L$. decidua. After this initial period, mortality rates decreased in $L$. decidua, but increased substantially in the pine species. P. cembra and $P$. mugo were then mainly killed by the pathogenic snow fungi Phacidium infestans ( $P$. cembra only) and Gremmeniella abietina (Senn 1999). L. decidua seedlings were younger at planting than the pine species (one year old instead of three to five years old), and this alone may explain differences in mortality in the first years after the afforestation. Thus, although the risk of weather damage can be higher when trees attain a certain height above the snow cover (e.g., Kharuk et al. 2010), the years when most trees are completely covered by snow in the early spring, and are therefore most susceptible to attacks by pathogenic fungi (in the case of pine species), may be the most critical stage determining the distribution of trees at the alpine treeline in the Alps at moist sites (Senn 1999). In the case of P. cembra in particular, Phacidium infestans only kills trees that are completely covered by snow, making small trees much more susceptible than larger trees (Senn 1999).

Although the relative importance of other variables changed, snowmelt date remained the most important variable for mortality and elevation the most important variable for growth over the entire 30 years. Even with the observed significant increase in air temperature during the 30-year period analyzed, elevation remained the most important factor for height growth and the second most important factor for mortality. This result indicates that the increase in temperature over time was not large enough to influence spatial patterns of tree survival and growth. Alternatively, elevation may be associated with other environmental factors in addition to temperature. The consistent influence of elevation on growth at Stillberg contrasts the findings by $\mathrm{Li}$ et al. (2004) in the Austrian Alps, where elevation effects on tree growth were only important once the trees exceeded 
$0.5 \mathrm{~m}$ above the snow surface. Although the elevation gradient covered was similar in both studies $(\sim 200 \mathrm{~m})$, the highest limit of the forests analyzed in Austria was close to the lowest point of Stillberg (2100 m a.s.1.).

The importance of solar radiation for height growth was life-stage dependent in our study and clearly declined over time (Fig. 5). This result is probably due to increased coupling of tree tissue temperatures to air temperatures as trees grow taller (Wardle 1981, Grace et al. 2002, Körner 2003, Li and Yang 2004) and reduced coupling to micro-site ground temperatures (Weisberg and Baker 1995, Smith et al. 2003, Daniels and Veblen 2004, Munier et al. 2010). During the first years after planting, shoot and root growth were mainly controlled by the microclimatic conditions at Stillberg (Schönenberger and Frey 1988, Häsler et al. 1999). Microtopography (mostly represented by radiation and snowmelt date in our study) can mimic temperature differences of relatively large elevational gradients over very short horizontal distances (Scherrer and Körner 2010). Before the Stillberg afforestation was established, growing-season temperatures measured for micro-sites with varying topography differed by $3^{\circ} \mathrm{C}$ at $3 \mathrm{~cm}$ depth (Turner et al. 1975).

Conversely, results from 2007 soil temperature logger measurements placed at a similar depth indicated that average soil temperatures during the growing season did not strongly differ between different micro-sites $\left(<1^{\circ} \mathrm{C}\right.$; I. Barbeito, unpublished data). Hence, these results support the observed pattern that once forests are closed and shade the ground, temperatures vary little over microtopography gradients (Körner and Paulsen 2004), and consequently, its influence on tree growth decreases. The increasing importance of wind on tree survival and height growth could be caused by an increase in mechanical damage as trees grow taller (Kajimoto et al. 2002, Kharuk et al. 2010), by a decrease of meristem temperature through wind chill (Grace et al. 1989) or by ice crystal abrasion of blowing snow (Hadley and Smith 1986). The importance of height above the ground for conifer seedlings growth is a phenomenon that has been observed in windy treeline areas and analogized to the escape of vertical stems on the leeward edges from krummholz mats (Smith et al. 2003).

\section{Conclusions}

Our 30-year study of close to 100000 trees demonstrates that established seedlings of three prominent high-elevation species are capable of surviving at $>100$ $\mathrm{m}$ above the current treeline in the Alps. However, the observed elevational thresholds in both tree growth and survival indicate a limited potential for the natural treeline to shift upward under the current climatic conditions. Our results provide novel insight into the complex and dynamic spatial interactions between snow cover, elevation, radiation, and wind in determining patterns of tree mortality and growth. Perhaps our most striking finding is that even small changes in the duration of snow cover in spring can have a great impact on species mortality patterns at the alpine treeline. The strong influence of this variable in our study indicates that treeline mortality models should focus on the spatial variation in snow cover, in addition to elevation. Future studies incorporating detailed micro-site measurements will be important for gaining a more mechanistic understanding of the patterns revealed in this large-scale investigation.

\section{ACKNOWLEDGMENTS}

We thank a large number of researchers, technicians, and students, who helped to build the basis for this 30-year experiment. Specifically, we thank Walter Schönenberger and Werner Frey for providing access to monitoring data from years before our own research on Stillberg began. We are also grateful to Ueli Wasem for his substantial contributions to field work during most of the monitoring period and for valuable discussions. For field assistance during the most recent survey and for data preparation, we thank Martina Forster and Sabine Blum. Setup and monitoring of this experiment was financed by the "Gebirgsprogramm" of WSL and SLF; co-funding for analysis and writing was provided by the CCES-Project MOUNTLAND and by the Swiss National Science Foundation (grant 315200-116861 to Christian Rixen). For statistical advice we thank Carolin Strobl, and for critical comments on this manuscript we thank Dominik Kulakowski and Veronica Lo. We also thank two anonymous reviewers for their comments on the paper.

\section{Literature Cited}

Anthelme, F., R. Michalet, L. Barbaro, and J. J. Brun. 2003. Environmental and spatial influences of shrub cover (Alnus viridis D.C.) on vegetation diversity at the upper treeline in the Inner Western Alps. Arctic, Antarctic and Alpine Research 35:48-55.

Auger, S., and S. Payette. 2010. Four millennia of woodland structure and dynamics at the Arctic treeline of eastern Canada. Ecology 91:1367-1379.

Bernouilli, M. 1998. Trockenmasse-Allokation in Bäumen an der Waldgrenze (Stillberg). Thesis. Botanical Institute, University of Basel, Basel, Switzerland.

Breiman, L. 2001. Random forests. Machine Learning 45:5-32.

Breiman, L., J. H. Friedman, R. A. Olshen, and C. J. Stone. 1984. Classification and regression trees. Wadsworth and Brooks/Cole, Monterey, California, USA.

Butler, D. R., G. P. Malanson, and D. M. Cairns. 1994. Stability of alpine treeline in Glacier National Park, Montana, U.S.A. Phytocoenologia 22:485-500.

Cairns, D. M. 2001. Patterns of winter desiccation in krummholz forms of Abies lasiocarpa at treeline sites in Glacier National Park, Montana, U.S.A. Geografiska Annaler 83:157-168.

Camarero, J. J., E. Gutiérrez, and M.-J. Fortin. 2006. Spatial patterns of plant richness across treeline ecotones in the Pyrenees reveal different locations for richness and tree cover boundaries. Global Ecology and Biogeography 15:182-191.

Carrer, M., and C. Urbinati. 2004. Age-dependent tree-ring growth responses to climate in Larix decidua and Pinus cembra. Ecology 85:730-740.

Cutler, D. R., T. C. Edwards, K. H. Beard, A. Cutler, K. T. Hess, J. Gibson, and J. J. Lawler. 2007. Random forests for classification in ecology. Ecology 88:2783-2792.

Daniels, L. D., and T. T. Veblen. 2004. Spatiotemporal influences of climate on altitudinal treeline in Northern Patagonia. Ecology 85:1284-1296. 
De'ath, G., and K. E. Fabricius. 2000. Classification and regression trees: a powerful yet simple technique for ecological data analysis. Ecology 81:3178-3192.

Devi, N., F. Hagedorn, P. Moiseev, H. Bugmann, S. Shiyatov, V. Mazepa, and A. Rigling. 2008. Expanding forests and changing growth forms of Siberian larch at the Polar Urals treeline during the 20th century. Global Change Biology $14: 1581-1591$.

Dullinger, S., T. Dirnbock, and G. Grabherr. 2004. Modelling climate change-driven treeline shifts: relative effects of temperature increase, dispersal and invisibility. Journal of Ecology 92:241-252.

Ellenberg, H. 1988. Vegetation ecology of Central Europe. Fourth edition. Cambridge University Press, Cambridge, UK.

Fortin, M.-J., and M. R. T. Dale. 2005. Spatial analysis: a guide for ecologists. Cambridge University Press, Cambridge, UK.

Frey, W. 1983. The influence of snow on growth and survival of planted trees. Arctic, Antarctic and Alpine Research 15:241251.

Gehrig-Fasel, J., A. Guisan, and N. E. Zimmermann. 2007. Tree line shifts in the Swiss Alps: Climate change or land abandonment? Journal of Vegetation Science 18:571-582.

Germino, M. J., N. J. Hasselquist, T. McGonigle, W. K. Smith, and P. P. Sheridan. 2006. Landscape- and age-based factors affecting fungal colonization of conifer seedling roots at the alpine tree line. Canadian Journal of Forest Research 36:901909.

Germino, M. J., and W. K. Smith. 2000. Differences in microsite, plant form, and low-temperature photoinhibition in alpine plants. Arctic, Antarctic and Alpine Research 32:388-396.

Germino, M. J., W. K. Smith, and A. C. Resor. 2002. Conifer seedling distribution and survival in an alpine treeline ecotone. Plant Ecology 162:157-168.

Grace, J., S. J. Allen, and C. Wilson. 1989. Climate and the meristem temperatures of plant communities near the treeline. Oecologia 79:198-204.

Grace, J., F. Berninger, and L. Nagy. 2002. Impacts of climate change on the tree line. Annals of Botany 90:537-544.

Hadley, J. L., and W. K. Smith. 1986. Wind effects on needles of timberline conifers: seasonal influence of mortality. Ecology 67:12-19.

Harsch, M. A., P. E. Hulme, M. S. McGlone, and R. P. Duncan. 2009. Are treelines advancing? A global metaanalysis of treeline response to climate warming. Ecology Letters 12:1040-1049.

Häsler, R., A. Streule, and H. Turner. 1999. Shoot and root growth of young Larix decidua in contrasting microenvironments near the Alpine timberline. Phyton 39:47-52.

Hastie, T. J., and R. J. Tibshirani. 1990. Generalized additive models. Chapman and Hall, New York, New York, USA.

Hättenschwiler, S., and W. K. Smith. 1999. Seedling occurrence in alpine treeline conifers: A case study from the central Rocky Mountains, USA. Acta Oecologica 20:219-224.

Havranek, W. M., and W. Tranquillini. 1995. Physiological processes during winter dormancy and their ecological significance. Pages 95-124 in W. K. Smith and T. N. Hinckley, editors. Ecophysiology of coniferous forests. Academic Press, San Diego, California, USA.

Holtmeier, F. K., and G. Broll. 2005. Sensitivity and response of northern hemisphere altitudinal and polar treelines to environmental change at landscape and local scales. Global Ecology and Biogeography 14:395-410.

Hothorn, T., K. Hornik, and A. Zeileis. 2006. Unbiased Recursive Partitioning: A Conditional Inference Framework. Journal of Computational and Graphical Statistics 15:651674.

Kajimoto, T., T. Seki, S. Ikeda, H. Daimaru, T. Okamoto, and H. Onodera. 2002. Effect of snowfall fluctuation on tree growth and establishment of subalpine Abies mariesii near upper forest limit of Mt. Yumori, Northern Japan. Arctic, Antarctic and Alpine Research 34:191-200.

Kharuk, V. I., K. J. Ranson, S. T. Im, and A. S. Vdovin. 2010. Spatial distribution and temporal dynamics of high-elevation forest stands in southern Siberia. Global Ecology and Biogeography 19:822-830.

Körner, C. 1998. A re-assesment of high elevation treeline positions and their explanation. Oecologia 115:445-459.

Körner, C. 2003. Alpine plant life: functional plant ecology of high mountain ecosystems. Springer-Verlag, Berlin, Germany.

Körner, C., and J. Paulsen. 2004. A world-wide study of high altitude treeline temperatures. Journal of Biogeography 31:713-732.

Kullman, L. 1986. Demography of Betula pubescens spp. tortuosa sown in contrasting habitats close to the birch tree-limit in central Sweden. Vegetatio 65:13-20.

Kullman, L. 1997. Tree-limit stress and disturbance a 25-year survey of geological change in the Scandes Mountains of Sweden. Geografiska Annaler 79:139-165.

Kullman, L. 2007. Tree line population monitoring of Pinus sylvestris in the Swedish Scandes, 1973-2005: implications for tree line theory and climate change ecology. Journal of Ecology 95:41-52.

Li, M. H., and J. Yang. 2004. Effects of microsite on growth of Pinus cembra in the subalpine zone of the Austrian Alps. Annals of Forest Science 61:319-325.

Mack, M. C., E. A. G. Schuur, M. S. Bret-Harte, G. R. Shaver, and F. S. Chapin, III. 2004. Ecosystem carbon storage in Arctic tundra reduced by long-term nutrient fertilization. Nature 431:440-443.

Maher, E. L., and M. J. Germino. 2006. Microsite differentiation among conifer species during seedling establishment at alpine treeline. Ecoscience 13:334-341.

Martin, M., K. Gavazov, C. Körner, S. Hättenschwiler, and C. Rixen. 2010. Reduced early growing season freezing resistance in alpine treeline plants under elevated atmospheric $\mathrm{CO}_{2}$. Global Change Biology 16:1057-1070.

Motta, R., and P. Nola. 2001. Growth trends and dynamics in sub-alpine forest stands in the Varaita Valley (Piedmont, Italy) and their relationships with human activities and global change. Journal of Vegetation Science 12:219-230.

Munier, A., L. Hermanutz, J. D. Jacobs, and K. Lewis. 2010. The interacting effects of temperature, ground disturbance, and herbivory on seedling establishment: implications for treeline advance with climate warming. Plant Ecology 210:19-30.

Müterthies, A. 2002. Struktur und Dynamik der oberen Grenze des Lärchen-Arvenwaldes im Bereich aufgelassener Alpweiden im Oberengadin. Dissertation. Work number 11. Institut für Landschaftsökologie, Münster, Germany.

Oberhuber, W. 2004. Influence of climate on radial growth of Pinus cembra within the alpine timberline ecotone. Tree Physiology 24:291-301.

Paulsen, J., and C. Körner. 2001. GIS-analysis of tree-line elevation in the Swiss Alps suggests no exposure effect. Journal of Vegetation Science 12:817-824.

$\mathrm{R}$ Development Core Team. 2009. R version 2.9.0. R Foundation for Statistical Computing, Vienna, Austria. http://cran.r-project.org/

Rolland, C., V. Petitcolas, and R. Michalet. 1998. Changes in radial tree growth for Picea abies, Larix decidua, Pinus cembra and Pinus uncinata near the alpine timberline since 1750. Trees 13:40-53.

Rossi, S., A. Deslauriers, T. Anfodillo, and V. Carraro. 2007. Evidence of threshold temperatures for xylogenesis in conifers at high altitude. Oecologia 152:1-12.

Scherrer, D., and C. Körner. 2010. Infra-red thermometry of alpine landscapes challenges climatic warming projections. Global Change Biology 16:2602-2613. 
Schönenberger, W., and W. Frey. 1988. Untersuchen zur Ökologie und Technik der Hochlagenaufforstung. Forschungsergebnisse aus dem Lawinenanrissgebiet Stillberg. Schweizerische Zeitschrift für Forstwesen 139:735-820.

Senn, J. 1999. Tree mortality caused by Gremmeniella abietina in a sublapine afforestation in the Central Alps and its relationship with duration of snow cover. European Journal of Forest Pathology 29:65-74.

Senn, U. 1952. Die Alpwirtschaft der Landschaft Davos. Geographica Helvetica 7:265-349.

Smith, W. K., M. J. Germino, T. E. Hancock, and D. M. Johnson. 2003. Another perspective on altitudinal limits of alpine timberlines. Tree physiology 23:1101-1112.

Speed, J. D. M., G. Austrheim, A. J. Hester, and A. Mysterud. 2010. Experimental evidence for herbivore limitation at the treeline. Ecology 91:3414-3420.

Strobl, C., A. L. Boulesteix, T. Kneib, T. Augustin, and A. Zeileis. 2008. Conditional variable importance for random forests. Bioinformatics 9:307.

Strobl, C., J. Malley, and G. Tutz. 2009. An introduction to recursive partitioning: Rationale, application and characteristics of classification and regression trees, bagging and random forests. Psychological Methods 14:323-348.

Sveinbjörnsson, B. 2000. North American and European treelines: External forces and internal processes controlling position. Ambio 29:388-395.

Tranquillini, W. 1979. Physiological Ecology of the Alpine timberline: Tree existence at high altitude with special reference to the European Alps. Ecological Studies number 31. Springer-Verlag, Berlin, Germany.
Turner, H., P. Rochat, and A. Streule. 1975. Thermische Charakteristik von Hauptstandortstypen im Bereich der oberen Waldgrenze (Stillberg, Dischmatal bei Davos). Eidgenössische Anstalt für das forstliche Versuchswesen Mitteilungen 51:95-119.

Vittoz, P., B. Rulence, T. Largey, and F. Frelechoux. 2008. Effects of climate and land-use change on the establishment and growth of cembran pine (Pinus cembra L.) over the alpine treeline ecotone in the Central Swiss Alps. Arctic, Antarctic and Alpine Research 40:225-232.

Wallentin, G., U. Tappeiner, J. Strobl, and E. Tasser. 2008. Understanding alpine tree line dynamics: An individualbased model. Ecological Modelling 218:235-246.

Wardle, P. 1981. Winter dessication of conifer needles simulated by artificial freezing. Arctic and Alpine Research 13:419-423.

Weisberg, P., and W. L. Baker. 1995. Spatial variation in tree seedling and krummholz growth in the forest-tundra ecotone of Rocky Mountain National Park, Colorado, USA. Arctic and Alpine Research 27:116-129.

Wieser, G., and M. Tausz. 2007. Trees at their upper limit. Treeline limitation at the alpine timberline. Springer-Verlag, Berlin, Germany.

Wipf, S., V. Stoeckli, and P. Bebi. 2009. Winter climate change in alpine tundra: plant responses to changes in snow depth and snowmelt timing. Climatic Change 94:105-121.

Wood, S. N. 2006. Generalized additive models: an introduction with R. Chapman and Hall, New York, New York, USA.

\title{
Supplemental Material
}

\section{Appendix A}

A figure showing the mean air temperature and the mean snowmelt date during the growing season (Ecological Archives E093037-A1).

\section{Appendix B}

A figure showing the mean spatial variation of snowmelt date along the elevation gradient across Stillberg (Ecological Archives E093-037-A2).

\author{
Appendix C
}

Decision trees for mortality in the periods 1975-1985 and 1975-1995 (Ecological Archives E093-037-A3).

Appendix D

Decision trees for height growth in the three 10-year periods studied (Ecological Archives E093-037-A4). 